\title{
DESENVOLVIMENTO PROFISSIONAL E PRECARIZAÇÃO DO TRABALHO DOCENTE: PERSPECTIVAS E (DES)CONTINUIDADES
}

\author{
DESARROLLO PROFESIONAL Y PREACARIZACIÓN DEL TRABAJO DOCENTE: \\ PERSPECTIVAS Y (DIS)CONTINUIDADES
}

\section{PROFESSIONAL DEVELOPMENT AND PREACARIZATION OF TEACHING WORK: PERSPECTIVES AND (DIS)CONTINUITIES}

\author{
Abília Ana de CASTRO NETA ${ }^{1}$ \\ Berta Leni Costa CARDOSO ${ }^{2}$ \\ Claudio Pinto NUNES ${ }^{3}$
}

RESUMO: Este texto apresenta uma reflexão no tocante ao fenômeno da Precarização do Trabalho e o Desenvolvimento Profissional Docente, em face das mudanças ocorridas no mundo do trabalho, impulsionadas pelos processos de reestruturação capitalista. Utilizou-se o recurso instrumental do questionário, contendo os eixos/elementos constitutivos das fases da carreira docente. Os dados revelaram um desenvolvimento profissional que é marcado por progressões e (des)continuidades, caracterizado, sobretudo, por uma trajetória profissional não linear, perpassando por atravessamentos psíquico-emocionais. Perfazemos este estudo estabelecendo que o Desenvolvimento Profissional Docente se apresenta por meio de uma trajetória não linear, complexa e contraditória, reflexo das relações marcadas pelo Estado capitalista. É necessário compreendê-lo por um viés histórico e crítico. Perpassando por uma compreensão de espaço-tempo, as fases da carreira docente não devem, portanto, ser tomadas como estáticas ou lineares, mas concebidas por meio de uma relação dialética, material e histórica.

PALAVRAS-CHAVE: Desenvolvimento profissional. Precarização do trabalho. Fases da carreira.

RESUMEN: Este texto presenta una reflexión sobre el fenómeno del Trabajo Precario y el Desarrollo Profesional Docente, frente a los cambios ocurridos en el mundo del trabajo, impulsados por los procesos de reestructuración capitalista. Se utilizó el recurso instrumental del cuestionario, que contiene los ejes / elementos que constituyen las fases de la carrera docente. Los datos revelaron un desarrollo profesional marcado por progresiones $y$ (dis) continuidades. Caracterizado, sobre todo, por una trayectoria profesional no lineal,

\footnotetext{
${ }^{1}$ Universidade Federal da Bahia (UFBA), Salvador - BA - Brasil. Doutoranda em Educação pelo Programa de Pós-Graduação em Educação (FACED/UFBA). ORCID: https://orcid.org/0000-0002-7222-5116. E-mail: bia_gbi@hotmail.com

${ }^{2}$ Universidade do Estado da Bahia (UNEB), Guanambi - BA - Brasil. Professora Titular (UNEB) e Docente do Programa de Pós-Graduação em Educação (UESB). Doutorado em Educação Física (UCB). ORCID: https://orcid.org/0000-0001-7697-0423.E-mail: bcardoso@uneb.br

${ }^{3}$ Universidade Estadual do Sudoeste da Bahia (UESB), Vitória da Conquista - BA - Brasil. Docente do Programa de Pós-Graduação em Educação. Doutorado em Educação (UFRN). Bolsista de Produtividade em Pesquisa do CNPq - Nível 2. ORCID: https://orcid.org/0000-0003-1514-6961. E-mail: claudionunesba@hotmail.com
} 
atravesando cruces psíquico-emocionales. Completamos este estudio estableciendo que el Desarrollo Profesional Docente se presenta a través de una trayectoria no lineal, compleja y contradictoria. Reflejo de las relaciones marcadas por el estado capitalista. Es necesario entenderlo desde un punto de vista histórico y crítico. Pasando por una comprensión del espacio-tiempo, las fases de la carrera docente no deben, por tanto, tomarse como estáticas o lineales, sino concebidas a través de una relación dialéctica, material e histórica.

PALABRAS CLAVE: Desarrollo profesional. Trabajo precario. Etapas de la carrera.

ABSTRACT: This text presents a reflection regarding the phenomenon of Precarious Work and Teacher Professional Development, in the face of the changes that occurred in the world of work, driven by the processes of capitalist restructuring. The instrumental resource of the questionnaire was used, containing the axes/elements constituting the stages of the teaching career. The data revealed a professional development that is marked by progressions and (dis) continuities. Characterized, above all, by a non-linear professional trajectory, going through psychic-emotional crossings. We completed this study by establishing that Teacher Professional Development presents itself through a non-linear, complex and contradictory trajectory. Reflection of the relations marked by the capitalist state. It is necessary to understand it from a historical and critical point of view. Passing through an understanding of space-time, the phases of the teaching career should not, therefore, be taken as static or linear, but conceived through a dialectical, material and historical relationship.

KEYWORDS: Professional development. Precarious work. Career stages.

\section{Introdução}

A temática abordada nesta investigação é concernente ao Desenvolvimento Profissional Docente e sua correlação com o fenômeno da Precarização do Trabalho. Nessa direção, de acordo com Marcelo García (2009, p. 9), “a denominação desenvolvimento profissional se adequa melhor à concepção do professor enquanto profissional do ensino". O autor preconiza que “o conceito 'desenvolvimento' tem uma conotação de evolução e continuidade que, em nosso entender, supera a tradicional justaposição entre formação inicial e formação contínua dos professores" (MARCELO GARCÍA, 2009, p. 9).

Nesta perspectiva, o Desenvolvimento Profissional Docente é entendido como: “[...] um processo individual e colectivo que se deve concretizar no local de trabalho do docente: a escola; e que contribui para o desenvolvimento das suas competências profissionais, através de experiências de índole diferente, tanto formais como informais" (MARCELO GARCÍA, 2009, p. 9). Contribuindo com esta perspectiva Najar e Lunardi (2020, p. 191) preconizam:

A formação permanente decorre de uma concepção de Desenvolvimento Profissional que deve considerar os sistemas e redes de ensino, o projeto 
pedagógico das escolas e o contexto onde está inserida, acompanhar a inovação e o desenvolvimento associados ao conhecimento, à ciência e à tecnologia, respeitar o protagonismo do professor e oferecer um espaçotempo que lhe permita refletir criticamente e aperfeiçoar sua prática, o diálogo e a parceria com atores e instituições competentes, capazes de contribuir para alavancar novos patamares de qualidade ao complexo trabalho de gestão da sala de aula e da instituição educativa.

Marcelo García (1999, p. 144) complementa esse entendimento ao preconizar que o desenvolvimento profissional é entendido, ainda, "como um conjunto de processos e estratégias que facilitam a reflexão dos professores sobre a sua própria prática, que contribui para que os professores gerem conhecimentos práticos, estratégicos e sejam capazes de aprender com a sua experiência". Day (2001, p. 15), por seu turno, aponta que "o sentido do desenvolvimento profissional dos professores depende das suas vidas pessoais e profissionais e das políticas e contextos escolares nos quais realizam a sua atividade docente”. Nessa direção,

[...] com base em Marcelo García (1999;2009), podemos entender que o Desenvolvimento Profissional Docente engloba a formação inicial, a formação continuada, a profissionalidade, os processos de autoformação e aprendizagens; ocorre ligado ao contexto de atuação, contextos de desenvolvimento organizacional e curricular; envolve processos de melhorias de competências e atitudes do professor, processos individuais e coletivos; implica (melhorias e influências das) as condições de trabalho; ocorre no âmbito pessoal; envolve as histórias de vida e a historicidade do sujeito, portanto, dá-se também no social; dá-se numa encruzilhada de caminhos que tende a unir práticas educativas, pedagógicas, escolares e de ensino. O DPD [desenvolvimento profissional docente] é um processo cheio de oscilações, variáveis e mudanças e sujeito a pressões; envolve e é influenciado por crenças e pelas experiências pessoais, experiência baseada no conhecimento formal (e informal), experiência escolar, ou seja, envolve e é influenciado pelas experiências anteriores ao curso de formação e à entrada na profissão [...]. Assim, envolve as próprias experiências. Baseia-se na reflexão e envolve a escola intimamente em seu processo. Sofre influência das políticas (salário, incentivos, autonomia, reformas etc.), da estrutura e cultura organizacional, e dos próprios professores - individual e coletivamente (logo, tem aspectos negativos (isolamento, por exemplo) e positivos). Portanto, o DPD multidimensional e sofre influências individuais, coletivas, emocionais, políticas, sociais, econômicas e profissionais. Nesse ínterim, implica saberes, fazeres, práticas e (re)construção da identidade profissional, pois o DPD é um processo também focado na pessoa do professor. Além disso, o DPD procura promover a construção de conhecimentos, as mudanças (no ensino, na escola, nos processos envolvidos e no professor) e a construção de aprendizagens (FERREIRA, 2020, p. 8, grifo nosso).

No tocante ao fenômeno da Precarização do Trabalho, de acordo com Piovezan (2017), o termo trabalho precário é mencionado pela literatura científica para caracterizar as 
novas condições de trabalho estabelecidas após a crise na década de 1970. Conforme Rosenfield (2011, p. 264), o trabalho precário é o: “[...] trabalho socialmente empobrecido, desqualificado, informal, temporário e inseguro, a noção de precarização aqui adotada remete a um processo social de institucionalização da instabilidade". Druck (2011, p. 41), por seu turno, estabelece que o trabalho precário está presente "[...] nas formas de inserção e de contrato, na informalidade, na terceirização, na desregulação e flexibilização da legislação trabalhista, no desemprego, [...] na perda salarial, na fragilidade dos sindicatos".

Nessa direção, a literatura aponta que o fenômeno da precarização impactou substancialmente o trabalho docente, com conotações negativas ao Desenvolvimento Profissional Docente, a saber: flexibilização, intensificação, descumprimento da legislação educacional, flexibilização das formas contratuais, perda de autonomia sobre o processo de trabalho, arrocho salarial, responsabilização, competitividade, desprofissionalização, degradação da força de trabalho, a educação e o labor da classe trabalhadora a serviço do capital, sofrimento psíquico, adoecimento e alienação dessa categoria profissional, como preconiza Piovezan (2017), bem como corroboram os achados de Castro Neta, Cardoso e Nunes (2021, no prelo), Castro Neta (2020), Castro Neta et al., (2020), Brito, Prado e Nunes (2017), Moura et al. (2019), Ilha e Hypolito (2014), Brito e Nunes (2020), Fardella e Sisto (2014), Robalino e Crespo (2014), Silva, Brito e Nunes (2019), Fernandes e Barbosa (2014), Duarte e Oliveira (2014), Fernandes e Barbosa (2014), Teixeira e Nunes (2016; 2019a; $2019 b ; 2019 c)$, entre outros pesquisadores da educação que investigam o trabalho docente. Nesta perspectiva, o presente estudo organiza-se no esforço de promover uma reflexão no tocante ao fenômeno da Precarização do Trabalho e o Desenvolvimento Profissional Docente, em face das mudanças ocorridas no mundo do trabalho, impulsionadas pelos processos de reestruturação capitalista.

Ferreira (2014) dialoga com teóricos que se debruçam sobre o ciclo profissional docente, a exemplo de Marcelo Garcia (1999), Bolívar (2002), Gonçalves (1992), entre outros. Conforme a autora, Marcelo Garcia (1999) analisa a teoria de Huberman (1992), preconizando que não há linearidade nas fases e não são experenciadas tal-qualmente. Bolívar (2002, p. 75-76), por seu turno, amplia a visão de carreira como sucessão de etapas de ascensão no trabalho, esclarecendo que o ciclo de vida dos professores,

[...] pode ser compreendido a partir da carreira profissional e associado ao desenvolvimento da vida no trabalho. O conceito de carreira é um dispositivo analítico formulado pelos sociólogos da Escola de Chicago, particularmente pela obra de Hughes (1958: 63) [...]. O curso profissional pode ser descrito pelo sujeito retrospectivamente ou antecipar aquilo que se 
espera - e, por isso mesmo, não se restringe às trajetórias profissionais associadas à ascensão no trabalho, contemplando também a experiência da vida como um todo.

O Desenvolvimento Profissional Docente é tido, portanto, como um fenômeno processual que sofre influências externas de cunho pessoal, profissional e contextual, compostas por mudanças, oscilações, descontinuidades e regressões. Justifica-se, assim, o fato das fases da carreira docente não serem estanques e/ou lineares (FERREIRA, 2014).

Também contribuíram para a compreensão das discussões aqui apresentadas os estudos de Tozetto e Domingues (2020), Silva, Raimann e Farias (2020), Cardoso Neto e Nez, (2020), Sobzinski, Diogo e Masson (2015), Souza e Mello (2019), Araújo, Pires e Ribas (2020), Ramos (2010), Magalhães e Anes (2015), Andrade, Moreira e Neves (2014), Brito, Silva e Nunes (2018), Ribeiro e Nunes (2018), Castro Neta, Cardoso e Nunes (2018), Maués e Costa (2020), Nunes e Oliveira (2017), Nunes (2019), Oliveira et al. (2018), Peroni e Oliveira (2019), Silva e Nunes (2019), Silva (2009), Socorro, Santos e Nunes (2017), Calazans e Nunes (2018), Rocha e Malheiro (2019), Machado (2018).

\section{Metodologia}

A compreensão construída pelo pesquisador acerca dos termos como conhecimento, ciência e método são basilares para se compreender suas escolhas em relação aos instrumentos e técnicas, assim como os princípios epistemológicos e metodológicos adotados em seu estudo (SOUZA; CRUZ, 2017). No que concerne ao método, Gatti (2012, p. 47) considera que “[...] não é algo abstrato. Método é ato vivo, concreto, que se revela nas nossas ações, na nossa organização do trabalho investigativo, na maneira como olhamos as coisas do mundo". Nessa direção, esse estudo inspirou-se pelos princípios ${ }^{4}$ do Materialismo Histórico Dialético, o qual busca conhecer as relações concretas e efetivas dos fenômenos, em termos de categorias básicas do marxismo: contradição, totalidade, classes, luta de classes e trabalho. Em virtude da especificidade da temática, fizemos opção metodológica pela investigação quanti-qualitativa, tendo em vista o seu caráter construtivo e processual.

Este estudo trata-se de um recorte da pesquisa mais ampla intitulada "A precarização do trabalho e os impactos para o processo de adoecimento da classe trabalhadora docente" (CASTRO NETA, 2020). Assim, foram pesquisados 25 docentes que atuam em uma instituição de ensino da Rede Estadual de Educação, localizada no interior do estado da

\footnotetext{
${ }^{4}$ Destacamos a palavra "princípios", pois, neste estudo, não adentramos na concretude do método, optamos por nos inspirar pelos pressupostos elementares do materialismo, respaldados pelas categorias marxistas: contradição, totalidade, classes, luta de classes e trabalho.
} 
Bahia. Utilizamos o recurso instrumental do questionário semiaberto, contendo os eixos/elementos constitutivos das fases da carreira docente estabelecidas por Ferreira (2014).

A operacionalização dessa pesquisa implicou na organização de dois momentos elementares, os quais se articulam, conferindo unidade em torno dos objetivos do estudo, quais sejam: o levantamento bibliográfico/estado da arte e a pesquisa de campo/empírica; de forma que as problematizações, debates e reflexões que serão desenvolvidos ao longo desse estudo serão produtos das interpretações e incorporação do referencial teórico, bem como das informações contidas nos documentos analisados.

No tocante à pesquisa de caráter bibliográfico - estado da arte, para o levantamento das produções acerca da temática deste estudo, tendo como critérios a relevância acadêmica e a abrangência do acervo, elegemos o catálogo de teses e dissertações da CAPES $^{5}$; o portal de periódicos da CAPES ${ }^{6}$; a biblioteca da $\mathrm{ANPED}^{7}$; a biblioteca do GESTRADO/UFMG ${ }^{8}$; o portal SCIELO ${ }^{9}$; e o banco de dissertações do PPGED/UESB ${ }^{10}$. Definimos como recorte temporal o período entre janeiro de 2014 a outubro de 2018. A consulta foi realizada considerando o descritor "Precarização do Trabalho Docente" buscando correlacioná-lo ao Desenvolvimento Profissional Docente. Após a leitura dos títulos e dos resumos dos resultados, alguns estudos foram descartados.

A partir dos apontamentos descritos acima, apresenta-se, a seguir, o gráfico extraído em decorrência do tratamento de dados do levantamento bibliográfico realizado, que podem contribuir para ilustrar o quantitativo de publicações que têm tratado da temática do presente estudo.

Gráfico 1 - Precarização do trabalho docente: Resultados

\footnotetext{
${ }^{5}$ Disponível em: http://catalogodeteses.capes.gov.br/catalogo-teses/\#!/. Acesso em: 10 out. 2020.

${ }^{6}$ Disponível em: http://www.periodicos.capes.gov.br/. Acesso em: 10 out. 2020.

${ }^{7}$ Disponível em: http://www.anped.org.br/biblioteca. Acesso em: 10 out. 2020.

${ }^{8}$ Disponível em: http://www.gestrado.net.br/. Acesso em: 10 out. 2020.

${ }^{9}$ Disponível em: http://www.scielo.org/php/index.php. Acesso em: 10 out. 2020.

${ }^{10}$ Disponível em: http://www2.uesb.br/ppg/ppged/?post type=producao. Acesso em: 10 out. 2020.
} 


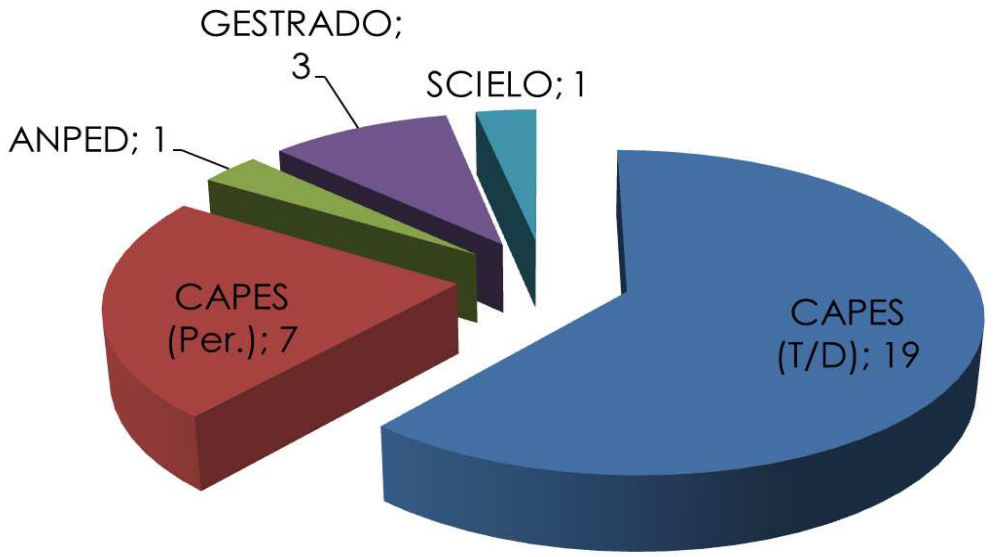

Fonte: Dados da pesquisa (2021)

Identifica-se, portanto, no banco de teses e dissertação da CAPES, 99 estudos. No entanto, somente 19 produções foram selecionadas; destas, 16 dissertações e 03 teses. Os valores diminuem nos demais portais de consulta, quais sejam: 07 artigos no portal de periódicos da CAPES (inicialmente foram identificadas 88 investigações); um estudo na biblioteca da ANPED (inicialmente foram identificados 03 estudos); 03 produções no GESTRADO, destes um verbete, um artigo e uma dissertação; e um artigo no portal SCIELO. O banco de dissertações do PPGED/UESB não apresentou resultados com base neste descritor.

No tocante aos cuidados éticos, a participação ocorreu de forma voluntária e foi confirmada através da assinatura do Termo de Consentimento Livre e Esclarecido (TCLE). O presente estudo foi aprovado pelo CEP da Universidade do Estado da Bahia, com o CAAE 43789015.4.0000.0057 e parecer número: 2.555.025. Para análise das informações obtidas no questionário organizamos um banco de dados no programa estatístico Statistical Package for Social Science (SPSS) e, a partir disso, foi realizada uma análise descritiva.

\section{Resultados e discussão}

Os dados a seguir caracterizam a amostra estudada. Traçamos, portanto, o perfil sociodemográfico dos sujeitos dessa pesquisa. De início, em relação à faixa etária, observamos que o grupo abrangeu todas as faixas etárias elencadas no questionário sociodemográfico. Destes, $16 \%$ possuem 20 a 29 anos de idade, $28 \%, 30$ a 39 anos de idade, 
$44 \%, 40$ a 49 anos de idade e $12 \%, 50$ anos ou mais. Nota-se, portanto, a prevalência de indivíduos com faixa etária entre 40 e 49 anos de idade.

No que concerne ao sexo dos sujeitos, $80 \%$ são do sexo feminino e $20 \%$ são do sexo masculino, o que coaduna com os achados científicos acerca da feminização da docência. Segundo Codo (1999), a grande presença feminina na profissão docente está relacionada à expansão do sistema educacional no país a partir da segunda metade do século XX, acompanhada da necessidade de recrutamento de trabalhadores para o ensino. Apesar de ser uma atividade desempenhada por ambos os sexos, naquela época, acreditava-se que a mulher poderia desenvolver melhor essa tarefa, devido ao fato de já exercer em seu domicílio o papel de cuidadora e educadora dos filhos, ou seja, aspectos considerados inerentes à atividade docente.

Quanto à situação civil, a proporção de solteiro(a) refere-se a $28 \%$, a proporção de casado(a) refere-se a 64\% e, no que concerne a divorciado(a) e viúvo(a), ambos se referem a 4\%. No tocante aos sujeitos dessa investigação, observa-se, portanto, a prevalência de indivíduos casados, notadamente, $64 \%$ da amostra. Todos os professores do estudo possuem grau de instrução de nível superior, e 96\% deles são pós-graduados (em nível de especialização e mestrado). Isso pode estar relacionado à aprovação da Lei de Diretrizes e Bases da Educação, em dezembro de 1996, que passou a exigir de todos os professores, em todos os níveis de ensino, formação de curso superior.

No tocante às fases da carreira, adotamos as fases elencadas por Ferreira (2014), que ilustra a realidade do professorado brasileiro, expressa nos quadros 01 e 02 :

Quadro 1 - Fases da carreira docente FEMININA: Modelo de Ferreira (2014)

\begin{tabular}{|c|c|}
\hline ANOS DE EXPERIÊNCIA & PERÍODOS \\
\hline $1-5$ & Iniciação \\
\hline $5-8$ & Estabilização \\
\hline $\mathbf{8 - 1 5}$ & Variação (+ ou -) \\
\hline $15-18$ & Examinação \\
\hline $\mathbf{1 8 - 2 0}$ & Serenidade \\
\hline $\mathbf{2 0 - 2 5}$ & Finalização \\
\hline
\end{tabular}

Fonte: Ferreira (2014, p. 48)

Quadro 2 - Fases da carreira docente MASCULINA: Modelo de Ferreira (2014) 


\begin{tabular}{|c|c|}
\hline ANOS DE EXPERIÊNCIA & PERÍODOS \\
\hline $1-5$ & Iniciação \\
\hline $5-8$ & Estabilização \\
\hline $8-14$ & Variação (+ ou -) \\
\hline $\mathbf{1 4 - 2 2}$ & Examinação \\
\hline $22-25$ & Serenidade \\
\hline $25-30$ & Finalização \\
\hline
\end{tabular}

Fonte: Ferreira (2014, p. 48)

Nessa direção, 24\% da amostra encontra-se na fase de iniciação, 4\% estabilização, $24 \%$ variação, $12 \%$ examinação e $36 \%$ finalização. Nenhum docente investigado encontra-se na fase de serenidade, como exposto no gráfico 02 :

Gráfico 2 - Fase da carreira

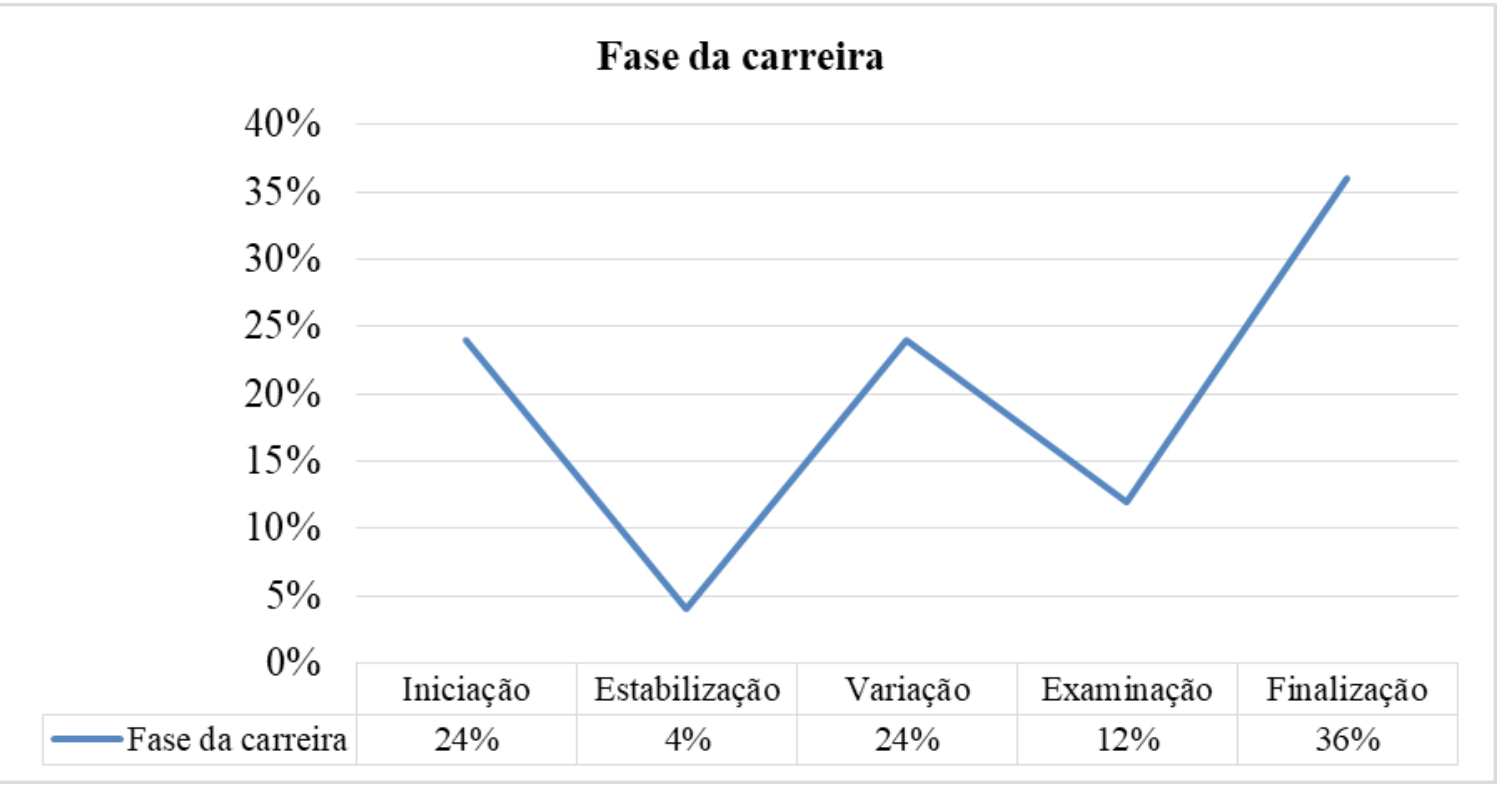

Fonte: Dados da pesquisa (2021)

As fases da carreira docente adotadas neste estudo foram sistematizadas por Ferreira (2014), as quais representam: Iniciação (01-05 anos) é período de entrada na carreira. O docente sente-se inseguro quanto ao desenvolvimento do seu trabalho. Sente os impactos da realidade concreta da vida laboral. As primeiras descobertas vão acontecendo e o professor percebe as contribuições da formação inicial, dos programas, dos diálogos e também as lacunas que estes deixaram. O aparecimento de dilemas é contínuo e há maior assimilação dos problemas, lamentação, angústia, cansaço, reclamações, fragilidade emocional, desilusão, insegurança etc. O professor vai modificando-se à medida que sofre também as pressões 
externas e se mostra muito vulnerável ao mal-estar docente, ao sofrimento psíquico e ao abandono da profissão.

Ferreira (2014) preconiza que a segunda fase é marcada pela estabilização na carreira (entre 06 e 08 anos). $\mathrm{O}$ docente sente-se seguro, confiante e age com segurança frente às problemáticas desenhadas no ambiente laboral. Há uma maturidade pedagógica e flexibilidade. O terceiro período é marcado pela variação experenciada pelos docentes, ora positivas, ora negativas (Período: 08-14/homens e 08-15/mulheres). Examinação é o período marcado pelos questionamentos sobre a carreira e as realizações positivas e negativas. Autoexaminação está ligada mais aos aspectos negativos da carreira (Período: 14-22/homens e 15-18/mulheres). A serenidade é o período marcado pela tranquilidade e maturidade no desenvolvimento profissional dos docentes. Há, ainda, um declínio afetivo entre professores e alunos (Período: 22-25/homens e 18-20/mulheres). O último período são os anos finais da carreira frente à aposentadoria; período esperado por uns e lamentado por outros (Finalização - Período: 25-30/homens e 20-25/mulheres). O fim da carreia é caracterizado por uma tendência de desinvestimento profissional, saturação e desencanto para uns e por uma renovação de interesse para outros (FERREIRA, 2014).

A fase de predominância dos docentes investigados é a finalização, correspondendo a $36 \%$ da amostra. Momento caracterizado, sobretudo, pelo desinvestimento na carreira. Nesta perspectiva, Cardoso (2017) preconiza que na realidade brasileira a fase do desinvestimento acontece prematuramente em função das precárias condições de trabalho, caracterizadas, sobretudo, pela assunção de baixos salários, a dupla ou tripla jornada de trabalho, a falta de recursos materiais e humanos nas escolas, intensificação e flexibilização do trabalho, entre outros aspectos, elementos que contribuem para que os professores não invistam na carreira e sejam acometidos pelo adoecimento e sofrimento psíquico. Além disso, muitos professores, por não encontrarem nessa profissão o retorno que almejavam, desistem logo no início da carreira.

No tocante às fases da carreira docente na literatura brasileira, Cardoso (2017) salienta que há uma carência significativa de pesquisas sobre o ciclo de carreira docente e uma necessidade de se olhar a carreira por um viés que seja mais amplo e que ultrapasse esse movimento marcado por etapas: início (busca), meio (estabilidade) e fim (reclusão), uma vez que podemos encontrar professores com significativo tempo de carreira e ainda em momento de ascensão.

A autora preconiza, ainda, que há linhas de força que coexistem nos momentos de transição de uma fase para outra. E ainda que existe um ciclo de carreira que acontece de 
forma individual e ao mesmo tempo coletivo, ou seja, cada professor vivencia e sente as fases da carreira de forma singular, a partir do seu contexto social e da sua singularidade, mas há nessa trajetória pontos de intercessão pelos quais todos passarão, o que torna o ciclo algo coletivo (CARDOSO, 2017).

\section{Considerações finais}

O Desenvolvimento Profissional Docente se apresenta por meio de uma trajetória não linear, complexa e contraditória, reflexo das relações marcadas pelo Estado capitalista. É necessário compreendê-lo por um viés histórico e crítico. Perpassando por uma compreensão de espaço-tempo, as fases da carreira docente não devem, portanto, ser tomadas como estáticas ou lineares, mas concebidas por meio de uma relação dialética, material e histórica. Os dados dos docentes investigados revelaram um desenvolvimento profissional que é marcado por progressões e (des)continuidades, caracterizado, sobretudo, por uma trajetória profissional não linear, perpassando por atravessamentos psíquico-emocionais.

No tocante à (des)continuidade na carreira, o mal-estar docente é um fator que afasta os docentes da sua função, interrompendo ou gerando instabilidade profissional. O termo malestar docente adotado por Esteve (1999) representa uma situação preocupante e bastante comum no cotidiano do professor, que se encontra invariavelmente descontente com suas condições de trabalho e, às vezes, consigo mesmo. De tal maneira que "[...] o mal-estar docente constituiu-se uma realidade constatada e estudada, a partir de diversas perspectivas, por diferentes trabalhos de investigação" (ESTEVE, 1999, p. 22). Para Souza e Leite (2011, p. 1109), a expressão mal-estar docente descreve os efeitos permanentes de caráter negativo que afetam a personalidade do professor, resultado das condições em que exerce a docência. A partir de tais condições, os docentes passam a manifestar sentimentos negativos intensos, como angústia, alienação, ansiedade e desmotivação, além de exaustão emocional, frieza perante as dificuldades dos outros, insensibilidade e postura desumanizada, comprometendo sobremaneira o seu desenvolvimento profissional.

\section{REFERÊNCIAS}

RIAEE - Revista Ibero-Americana de Estudos em Educação, Araraquara, v. 16, n. 3, p. 2067-2082, jul./set. 2021. e-ISSN: 1982-5587 
ANDRADE, A. C.; MOREIRA, L. G.; NEVES, M. S. S. A lógica de mercado e o mundo do trabalho na formação de engenheiros. Revista Práxis Educacional, Vitória da Conquista, v. 16, n. 41, p. 208-235, 2020. DOI: 10.22481/praxisedu.v16i41.7261

ARAÚJO, S. B.; PIRES, E. D. P. B.; RIBAS, G. F. Valorização, precarização e reconhecimento dos professores de creches universitárias. Revista Ibero-Americana de Estudos em Educação, Araraquara, v. 15, n. 1, p. 221-235, 2020.

DOI:10.21723/riaee.v15i1.12780

BOLÍVAR, A. (org.). Profissão professor: o itinerário profissional e a construção da escola. Trad. Gilson César Cardoso de Souza. Bauru, SP: EDUSC, 2002.

BRITO, C. D. A. S.; NUNES, C. P. A intensificação do trabalho docente no contexto da mercantilização da educação superior no Brasil. Journal of Research and Knowledge Spreading, Maceió, v. 1, n. 1, 2020. Disponível:

https://www.seer.ufal.br/index.php/jrks/article/view/11420. Acesso em: 10 dez. 2020.

BRITO, R. S.; PRADO, J. R.; NUNES, C. P. As condições de trabalho docente e o pós-estado de bem-estar social. Revista Tempos e Espaços em Educação, v. 10, n. 23, p. 165-174, 2017. DOI: 10.20952/revtee.v10i23.6676

BRITO, V. L. F.; SILVA, D. O. V; NUNES, C.P. Formação docente e currículo: desafios contemporâneos. Revista Linguagens, Educação e Sociedade, v. 23, 2018. Disponível em: https://revistas.ufpi.br/index.php/lingedusoc/article/view/8397. Acesso em: 19 nov. 2020.

CALAZANS, D. P. P.; NUNES, C. P. Reflexos sobre a formação docente no contexto atual: entre a subserviência e a crítica. Teoria e Prática da Educação, v. 21, n. 3, p. 41-52, 2018. DOI: $10.4025 /$ tpe.v21i3.45421

CARDOSO NETO, O. F.; NEZ, E. Plano municipal de educação (PME): valorização e desafios da carreira docente. Revista Ibero-Americana de Estudos em Educação, Araraquara, v. 15, n. esp. 1, p. 796-809, 2020. DOI: 10.21723/riaee.v15iesp.1.13350

CARDOSO, S. Ciclo de carreira docente: o que dizem as pesquisas brasileiras? In: CONGRESSO NACIONAL DE EDUCAÇÃO, 13., 2017, Curitiba. Anais [...]. Curitiba, PR: EDUCERE, 2017.

CASTRO NETA, A. A.; CARDOSO, B. L. C.; NUNES, C. P. Reformas educacionais no contexto pós-golpe de 2016. Revista Educação em Debate, Fortaleza, v. 40, n. 77, p. 162$174,2018$.

CASTRO NETA, A. A. A precarização do trabalho e os impactos para o processo de adoecimento da classe trabalhadora docente. 2020. 220 f. Dissertação (Mestrado em Educação) -Universidade Estadual do Sudoeste da Bahia, Vitória da Conquista, 2020.

CASTRO NETA, A. A. et al. Contextos da precarização docente na educação brasileira. Revista Exitus, v. 10, n. 1, e020037, 2020. DOI: 10.24065/2237-9460.2020v10n0ID1261

CASTRO NETA, A. A.; CARDOSO, B. L. C.; NUNES, C. P. O adoecimento docente: um produto do capitalismo. Linguagens Educação Sociedade LES, 2021. No prelo. 
CODO, W. (coord.). Educação: carinho e trabalho. Petrópolis: Vozes, 1999.

DAY, C. Desenvolvimento profissional de professores: os desafios da aprendizagem permanente. Porto: Porto Editora, 2001.

DRUCK, G. Trabalho, precarização e resistências: novos e velhos desafios? Cadernos CRH, Salvador, v. 24, p. 37-57, 2011.

DUARTE, A. W. B.; OLIVEIRA, D. A. Valorização profissional docente nos sistemas de ensino de Minas Gerais e Pernambuco. Revista Práxis Educacional, Vitória da Conquista, v. 10, n. 17, p. 67-97, 2014. Disponível em: https://periodicos2.uesb.br/index.php/praxis/article/ view/780. Acesso em: 12 ago. 2020.

ESTEVE, J. M. O mal-estar docente: a sala de aula e a saúde dos professores. Bauru, SP: EDUSC, 1999.

FARDELLA, C.; SISTO, V. La constitución de la profesión docente y su vínculo con la construcción de Estado y política educativa en Chile. Revista Práxis Educacional, Vitória da Conquista, v. 10, n. 17, p. 17-49, 2014. Disponível em: https://periodicos2.uesb.br/index.php/ praxis/article/view/776. Acesso em: 12 ago. 2020.

FERNANDES, M. J. S.; BARBOSA, A. O trabalho docente na rede pública do estado de São Paulo: apontamentos iniciais para a discussão da jornada de trabalho. Revista Práxis Educacional, Vitória da Conquista, v. 10, n. 17, 117-142, 2014. Disponível em: https://periodicos2.uesb.br/index.php/praxis/article/view/782. Acesso em: 12 ago. 2020.

FERREIRA, L. G. Desenvolvimento profissional docente: percursos teóricos, perspectivas e (des)continuidades. Educação em Perspectiva, Viçosa, v. 11, p.1-18, 2020.

FERREIRA, L. G. Professores da zona rural em início de carreira: narrativas de si e desenvolvimento profissional. 2014. 273 f. Tese (Doutorado em Educação) - Universidade Federal de São Carlos, São Carlos, 2014.

GATTI, B. A. A construção da pesquisa em educação no Brasil. Brasília, DF: Líber Livro Editora, 2012.

GONÇALVES, J. A. M. A carreira das professoras do ensino primário. In: NÓVOA, A. (org.). Vidas de professores. Porto: Porto Editora, 1992. p. 141-169.

HUBERMAN, M. O ciclo de vida profissional dos professores. In: NÓVOA, A. (org.). Vida de professores. 2. ed. Porto: Porto Editora, 1992, p. 31-61.

ILHA, F. R. S.; HYPOLITO, Á. M. O trabalho docente no início da carreira e sua contribuição para o desenvolvimento profissional do professor. Revista Práxis Educacional, Vitória da Conquista, v. 10, n. 17, p. 99-114, 2014. Disponível em:

https://periodicos2.uesb.br/index.php/praxis/article/view/781. Acesso em: 12 ago. 2020.

MACHADO, L. B. Profissão docente: elementos demarcadores das representações sociais de professores em início de carreira. Revista Ibero Americana de Estudos em Educação, 
Araraquara, v. 13, n. 03, p. 1132-1148, jul./set. 2018. DOI: DOI: 10.21723/riaee.v13.n3.2018.9094

MAGALHÃES, S. M. O.; ANES, R. R. M. O trabalho docente na contemporaneidade: da resignação à emancipação. Revista Práxis Educacional, Vitória da Conquista, v. 12, n. 23, p. 223-249, 2015. Disponível em: https://periodicos2.uesb.br/index.php/praxis/article/view/913. Acesso em: 12 ago. 2020.

MARCELO GARCÍA, C. Desenvolvimento profissional: passado e futuro. Sísifo-Revista das Ciências da Educação, Lisboa, n. 8, p. 7-22, jan./abr. 2009.

MARCELO GARCIA, C. Formação de professores: para uma mudança educativa. Porto: Porto Editora. 1999.

MAUÉS, O. C.; COSTA, M. C. S. A OCDE e a formação docente: a TALIS em questão. Revista Práxis Educacional, Vitória da Conquista, v. 16, n. 41, p. 99-124, 2020. DOI: 10.22481/praxisedu.v16i41.7255

MOURA, J. S. et al. A precarização do trabalho docente e o adoecimento mental no contexto neoliberal. Revista Profissão Docente, v. 19, n. 40, 2019. Disponível em:

http://www.revistas.uniube.br/index.php/rpd/article/view/1242. Acesso em: 21 set. 2020.

NAJAR, M. I. P.; LUNARDI, E. M. Desenvolvimento profissional docente na perspectiva da participação sindical: diálogos propositivos para qualificação do plano de carreira dos professores municipais de Santa Maria-RS. Revista Ibero-Americana de Estudos em Educação, Araraquara, v. 15, n. 1, p. 189-205, jan./mar.2020. DOI: 10.21723/riaee.v15i1.13114

NUNES, C. P. Formación y trabajo docente: cuestiones contemporáneas. Revista Exitus, v. 9, n. 3, p. 19-32, 2019. DOI: 10.24065/2237-9460.2019v9n3ID917

NUNES, C. P.; OLIVEIRA, D. A. Trabalho, carreira, desenvolvimento docente e mudança na prática educativa. Educação e Pesquisa, São Paulo, v. 43, n. 1, p. 65-80, 2017. DOI: 10.1590/s1517-9702201604145487

OLIVEIRA, E. G. et al. Desenvolvimento profissional docente: um olhar para além da formação. Educa - Revista Multidisciplinar em Educação, v. 5, n. 12, p. 23-39, 2018. DOI: $10.26568 / 2359-2087.2018 .3254$

PERONI, V. M. V.; OLIVEIRA, C. M. B. O marco regulatório e as parcerias públicoprivadas no contexto educacional. Revista Práxis Educacional, v. 15, n. 31, p. 38-57, 2019. DOI: $10.22481 /$ praxis.v15i31.4657

PIOVEZAN, P. R. As políticas educacionais e a precarização do trabalho docente no Brasil e em Portugal. 2017. 225 f. Tese (Doutorado em Educação) - Faculdade de Filosofia e Ciências, Universidade Estadual Paulista, Marília, 2017.

RAIMANN, A.; FARIAS, R. H. S. Plano municipal de educação e o trabalho docente sob tensões. Revista Ibero-Americana De Estudos Em Educação, v. 15, n. esp. 1, p. 780-795, 2020. DOI: 10.21723/riaee.v15iesp.1.13349 
RAMOS, G. P. FUNDEF versus FUNDEB: uma análise introdutória sobre a continuidade e as descontinuidades da política de valorização docente. Revista Ibero-Americana De Estudos Em Educação, v. 4, n. 1, p. 122-132, 2010. DOI: 10.21723/riaee.v4i1.2696

RIBEIRO, J. C. O. A.; NUNES, C. P. Formação de professores no contexto neoliberal. Colloquium Humanarum, v. 15, n. 4, p. 57-71, 2018.

ROBALINO, M.; CRESPO, C. Repensar las sociedades, repensar la formación de los docentes. Revista Práxis Educacional, Vitória da Conquista, v. 10, n. 17, p. 51-65, 2014. Disponível em: https://periodicos2.uesb.br/index.php/praxis/article/view/779. Acesso em: 12 ago. 2020.

ROCHA, C. J. T.; MALHEIRO, J. M. S. Narrativas identitárias em experiência de transformação e desenvolvimento profissional docente. Revista Ibero-Americana de Estudos em Educação, Araraquara, v. 14, n. 3, p. 986-1000, jul./set. 2019. DOI: 10.21723/riaee.v14i3.11836

ROSENFIELD, C. L. Trabalho decente e precarização. Tempo social, São Paulo, v. 23, n. 1, p. 247-268, jun. 2011.

SILVA, D. O. V.; BRITO, V. L. F.; NUNES, C. P. Valorização docente na conjuntura do pós impeachement de 2016 no Brasil. Revista Cocar, v. 13, n. 26, p. 1-20, maio/ago. 2019.

SILVA, D. O. V.; NUNES, C. P. Plano de carreira enquanto estratégia de resistência para a valorização docente no território de identidade do sudoeste baiano. Revista Educação e Emancipação, São Luís, v. 12, n. 3, p. 93-113, 2019. DOI: 10.18764/2358-4319.v12n3p93113

SILVA, N. R. G. Gestão escolar democrática: uma contextualização do tema. Revista Práxis Educacional, Vitória da Conquista, v. 5, n. 6, jan./jun. 2009.

SOBZINSKI, J. S.; DIOGO, E. M.; MASSON, G. Políticas de formação e valorização docente: uma análise do plano de desenvolvimento da educação e das metas do novo plano nacional de educação. Revista Ibero-Americana de Estudos em Educação, Araraquara, v. 10, n. 4, p. 1212-1233, 2015. DOI: 10.21723/riaee.v10i4.6407

SOCORRO, P. E. V.; SANTOS, A. R.; NUNES, C. P. Políticas públicas educativas na América Latina. Revista Educação Em Questão, v. 55, n. 45, p. 12-41, 2017. DOI: 10.21680/1981-1802.2017v55n45ID12743

SOUZA, A. N.; LEITE, M. P. Condições de trabalho e suas repercussões na saúde dos professores da educação básica no Brasil. Educação e Sociedade, Campinas, v. 32, n. 117, p. 1105-1121, out./dez. 2011.

SOUZA, E. C.; CRUZ, N. S. Pesquisa (auto)biográfica: sentidos e implicações para o campo educacional. In: AMADO, J.; CRUSOÉ, N. M. C. (org.). Referenciais teóricos e metodológicos de investigação em educação e ciências sociais. Vitória da Conquista: Edições UESB, 2017. 219 p. 
SOUZA, V. E. B.; MELLO, R. M. A V. Uma breve reflexão do percurso das políticas públicas educacionais no Brasil: em foco a formação continuada. Revista Ibero-Americana de Estudos em Educação, Araraquara, v. 14, n. 1, p. 94-107, 2019. DOI: 10.21723/riaee.v14i1.8654

TEIXEIRA, E. C. N. S.; NUNES, C. P. O piso salarial como insumo da valorização docente nos governos de FHC e Lula: da política de fundos à Lei do Piso. Revista Práxis Educacional, v. 12, n. 23, p. 251-270, 2016.

TEIXEIRA, E. C. N. S.; NUNES, C. P. A valorização docente e a lei do piso salarial: um estado da arte. Educação e Cultura Contemporânea, v. 16, n. 42, p. 437-452, 2019a.

TEIXEIRA, E. C. N. S.; NUNES, C. P. O Piso Salarial Nacional no Contexto do Financiamento da Educação no Brasil: limites e possibilidades do seu cumprimento. FINEDUCA: Revista de Financiamento da Educação, v. 9, n. 22, p. 1-17, 2019b. DOI: 10.22491/fineduca-2236-5907-v9-90205

TEIXEIRA, E. C. N. S.; NUNES, C. P. Os sentidos atribuídos ao piso salarial nacional como política pública de valorização docente. Revista Tempos e Espaços em Educação, Aracaju, v. 12 , n. 29, p. 195-212, 2019c.

\section{Como referenciar este artigo}

CASTRO NETA, A. A.; CARDOSO, B. L. C.; NUNES, C. P. Desenvolvimento profissional e precarização do trabalho docente: perspectivas e (des)continuidades. Revista IberoAmericana de Estudos em Educação, Araraquara, v. 16, n. 3, p. 2067-2082, jul./set. 2021. e-ISSN: 1982-5587. DOI: https://doi.org/10.21723/riaee.v16i3.14842

Submetido em: $15 / 10 / 2020$

Revisões requeridas em: 17/11/2020

Aprovado em: 10/12/2020

Publicado em: 01/07/2021 